Ryner Jose C. Carrillo, MD, MSc

Departments of Anatomy and Otorhinolaryngology College of Medicine - Philippine General Hospital University of the Philippines Manila
Correspondence: A/Prof. Dr. Ryner Jose C. Carrillo Department of Anatomy, College of Medicine University of the Philippines Manila

Pedro Gil St., Ermita, Manila 1000

Philippines

Phone number: (632) 5264194

E-mail add:ryner_c@yahoo.com

Reprints will not be available from the author.

The author declared that this represents original material that is not being considered for publication or has not been published or accepted for publication elsewhere, in full or in part, in print or electronic media; that the manuscript has been read and approved by the author, that the requirements for authorship have been met by the author, and that the author believes that the manuscript represents honest work.

Disclosures: The author signed a disclosure that there are no financial or other (including personal) relationships, intellectual passion, political or religious beliefs and institutional affiliations that might lead to a conflict of interest.

\section{Pterygoid Botolinum Toxin Injection}

Botolinum is a toxic polypeptide produced by the gram-positive anaerobic bacterium Clostridium botulinum that inhibits acetylcholine release from nerve endings, resulting in reduced neuromuscular transmission and local muscle activity, as well as cholinergic mediated parasympathetic activities.' Its name is derived from the Latin word botulus, meaning sausage, as its toxicity was initially attributed to the oil of spoiled sausages. Of late, botolinum, packaged in various commercial forms such as onabotulinumtoxinA (Botox ${ }^{\oplus}$ type A, Allergan, Irvine, CA), is popularly used in several medical applications such as blepharospasm, hyperhidrosis and strabismus, and most famously in cosmetic surgery, where Botox ${ }^{\circledR}$ injections are used to eliminate and/or smoothen wrinkles.

In otolaryngology, common indications for Botox ${ }^{\circledR}$ injections include management of rhytids, cervical dystonia and spasmodic dysphonia. Another interesting application is pterygoid muscle injection. The lateral pterygoid muscles (LPM) pull the condylar head of the jaw forward, resulting in the opening of the jaw or displacement of the mandible anteriorly or towards the contralateral side, whereas the medial pterygoid muscles (MPM) pull the angle of the jaw upward and anteriorly to close or protrude the jaw, respectively. Increased or unequal activity of these muscles relative to other muscles of mastication and temporomandibular joint ligaments may result in asymmetry, malocclusion, temporo-mandibular joint (TMJ) dysfunction or dislocation. ${ }^{2}$ Indications for pterygoid muscle botox injection include neurogenic TMJ dislocation, recurrent TMJ dislocation, oromandibular dystonia (OMD) particularly LPM dystonia, LPM spasm in condylar fractures, TMJ clicking, bruxism with myofascial pain and stroke-induced trismus.-20

Several patients with indications for Botox ${ }^{\circledast}$ injection of the pterygoid muscle have been seen by this author, including post cerebro-vascular disease (CVD) dystonia with recurrent TMJ dislocation, bruxism, condylar fracture and oromandibular dystonia, but only the latter had the opportunity to acquire Botox ${ }^{\otimes}$ and the electrode needle (Ambu ${ }^{\circ}$ Neuroline Inoject $50 \mathrm{~mm} / 2^{\prime \prime}$ length $\times 0.50 \mathrm{~mm} / 25$ Gauge Calibre, Ambu A/S, Denmark) due to cost constraints. We used a Caldwell Sierra Wave $\mathrm{V}$ Electromyography (EMG) Machine with v. 10.0.125 software (Caldwell Laboratories, Inc., Kennewick, WA). The most exciting parts of performing the procedure are the anatomy and process of identifying the muscle with EMG guidance and the immediate results after injection.

Electromyography (EMG) - guided botolinum injection can measure muscle activity by recording muscle depolarization or electrical activity. Using cannula needle electrodes with an open lumen, the muscles are identified by their activity during muscle contraction and then injected with Botox ${ }^{\oplus}$ to decrease muscle activity. Anatomically, the LPM is accessible through the mandibular notch which is directly anterior to the condylar head of the mandible. The latter is easily palpable and is anterior to the external auditory canal (Figure 1). Using a needle electrode, the LPM can be identified by opening the jaw or moving the jaw to the contralateral side.,21 The 


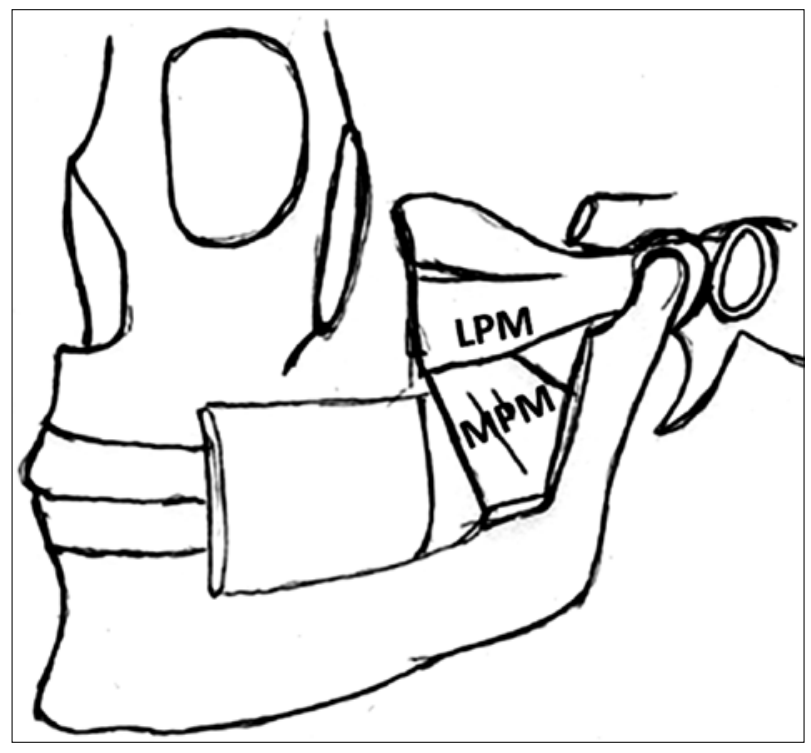

Figure 1. Infratemporal fossa with zygomatic arch and coronoid process removed. LPM - lateral pterygoid muscle, MPM - medial pterygoid muscle

MPM is less easily targeted because it generally closes the jaw. However, to further decrease anterior displacement of the jaw, both the LPM and the MPM activity can be decreased. The MPM can be targeted transorally by inserting the EMG electrode medial to the jaw and lateral to the pterygomandiular raphe, piercing through the buccinator muscle. Identifying MPM contraction can be done by biting to occlude the upper and lower jaw. With the cheeks retracted and needle inserted, Botox ${ }^{\circledR}$ injection can be done to lower MPM activity.

Clinical outcome can be assessed by measuring inter-incisor distance, mandibular deviation and protrusion, decrease in pain, restoration of masticatory function and proper occlusion. The dosage of botolinum injection in the pterygoid muscles will vary between indications and the specific toxin product used, but is usually in the range of $20-30 \mathrm{U} / \mathrm{ml}$. Injection dose is $10 \mathrm{U}$ to $50 \mathrm{U}$ per muscle every three months, ${ }^{20}$ with a total limit of $200 \mathrm{U}$ for muscles of mastication. In the author's experience, the 20 units of Botox ${ }^{\circledast}$ wear off at two months after injection in a patient with oromandibular dystonia.

Pterygoid Botox ${ }^{\circledast}$ injection can be an important ancillary to rehabilitation disorders of mastication and the TMJ. However, it is not without risk. Various complications have been reported such as changes in salivary consistency, swallowing and speech and facial muscle weakness. ${ }^{20}$ These complications may be attributed to the toxin diffusing to untargeted adjacent structures such as the parotid gland, facial muscles and superior constrictors. Proper technique, sufficient knowledge of pterygoid anatomy and EMG guidance are important in preventing complications. Clinical outcomes for both short- and long-term goals still need to be standardized and defined to allow for comparison across different case series and trials. A multidisciplinary approach cannot be overemphasized.

\section{Pearls:}

1. Short-term and long-term goals should be set.

2. Zygomatic arch and condylar head are good landmarks for lateral pterygoid injection via extra-oral approach.

3. Coronoid process and ramus can be palpated intra-orally when doing medial pterygoid muscle injection. The needle is guided medial to the bone, piercing the retromolar trigone.

4. EMG guidance when using cannula electrodes to inject Botox will facilitate muscle identification.

5. Proper dosing and frequency of Botox injection is individualized.

REFERENCES

1. Ramachandran TS, Molloy FM. Botulinum Toxin (BOTOX (R)), Dystonia Treatment [monograph on the Internet]. . Medscape, LLC; 2010 [cited 2011 May 6]. Available from: http://emedicine. medscape.com/article/1818592-overview.

2. Moore K. Clinically oriented anatomy. 3rd ed. Baltimore: William and Wilkins; 1992.

3. Schwartz M, Freund B. Treatment of temporomandibular disorders with botulinum toxin. Clin J Pain. 2002 Nov-Dec;18(6 Suppl):S198-203.

4. Karacalar A, Yilmaz N, Bilgici A, Baş B, Akan H. Botulinum toxin for the treatment of temporomandibular joint disk disfigurement: clinical experience. J Craniofac Surg. 2005 May;16(3):476-81.

5. Michelotti A, Silva R, Paduano S, Cimino R, Farella M. Oromandibular dystonia and hormonal factors: twelve years follow-up of a case report. J Oral Rehabil. 2009 Dec;36(12):916-21. Epub 2009 Oct 14.

6. Mendes RA, Upton LG. Management of dystonia of the lateral pterygoid muscle with botulinum toxin A. Br J Oral Maxillofac Surg. 2009 Sep;47(6):481-3. Epub 2008 Oct 1.

7. Vazquez-Delgado $E$, Okeson JP. Treatment of inferior lateral pterygoid muscle dystonia with zolpidem tartrate, botulinum toxin injections, and physical self-regulation procedures: a case report.Cranio. 2004 Oct:22(4):325-9.

8. Vázquez Bouso O, Forteza González G, Mommsen J, Grau VG, Rodríguez Fernández J, Mateos Micas M. Neurogenic temporomandibular joint dislocation treated with botulinum toxin report of 4 cases . Oral Surg Oral Med Oral Pathol Oral Radiol Endod. 2010 Mar; 109(3):e33-7.

9. Fu KY, Chen HM, Sun ZP, Zhang ZK, Ma XC. Long-term efficacy of botulinum toxin type A for the treatment of habitual dislocation of the temporomandibular joint. Br J Oral Maxillofac Surg 2010 Jun;48(4):281-4. Epub 2009 Aug 7

10. Møller E, Bakke M, Dalager T, Werdelin LM. Oromandibular dystonia involving the lateral pterygoid muscles: four cases with different complexity. Mov Disord. 2007 Apr 30;22(6):78590.

11. Yoshida $\mathrm{K}$, lizuka $\mathrm{T}$. Botulinum toxin treatment for upper airway collapse resulting from temporomandibular joint dislocation due to jaw-opening dystonia. Cranio. 2006 Jul;24(3):21722

12. Gilles R, Magistris MR, Hugentobler M, Jaquinet A, Richter M. Treatment of recurrent luxation of the temporomandibular joint with botulinum toxin.Rev Stomatol Chir Maxillofac. 2000 Oct;101(4):189-91.

13. Ziegler CM, Haag C, Mühling J. Treatment of recurrent temporomandibular joint dislocation with intramuscular botulinum toxin injection.Clin Oral Investig. 2003 Mar;7(1):52-5. Epub 2003 $\operatorname{Jan} 25$

14. Daelen B, Thorwirth V, Koch A. Treatment of recurrent dislocation of the temporomandibular joint with type A botulinum toxin. Int J Oral Maxillofac Surg. 1997 Dec;26(6):458-60.

15. Bakke M, Møller E, Werdelin LM, Dalager T, Kitai N, Kreiborg S. Treatment of severe temporomandibular joint clicking with botulinum toxin in the lateral pterygoid muscle in two cases of anterior disc displacement. Oral Surg Oral Med Oral Pathol Oral Radiol Endod. 2005 Dec;100(6):693-700.

16. Canter HI, Kayikcioglu A, Aksu M, Mavili ME. Botulinum toxin in closed treatment of mandibular condylar fracture. Ann Plast Surg. 2007 May;58(5):474-8.

17. Spillane KS, Shelton JE, Hasty MF. Stroke-induced trismus in a pediatric patient: long-term resolution with botulinum toxin A. Am J Phys Med Rehabil. 2003 Jun;82(6):485-8.

18. Guarda-Nardini L, Manfredini D, Salamone M, Salmaso L, Tonello S, Ferronato G. Efficacy of botulinum toxin in treating myofascial pain in bruxers: a controlled placebo pilot study. Cranio. 2008 Apr;26(2):126-35.

19. Arinci A, Güven E, Yazar M, Başaran K, Keklik B. Effect of injection of botulinum toxin on lateral pterygoid muscle used together with the arthroscopy in patients with anterior disk displacement of the temporomandibular joint. Kulak Burun Bogaz Ihtis Derg. 2009 May-Jun;19(3):122-9.

20. Clark GT. The management of oromandibular motor disorders and facial spasms with injections of botulinum toxin.Phys Med Rehabil Clin N Am. 2003 Nov;14(4):727-48.

21. Cardona-Garcia OD, Higgins DSJr,Molho ES. Botulinum toxin in the management of dystonia. Current Treatment Options in Neurology 2 